\section{Total care means total transparency}

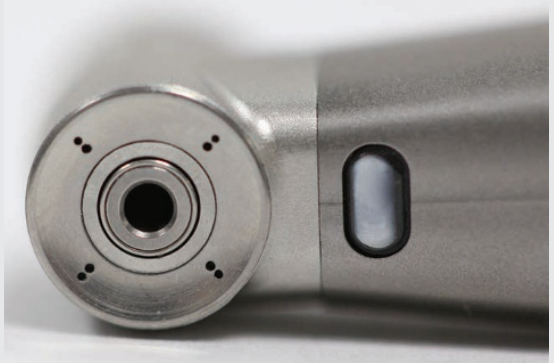

B.A. International, the UK's leading handpiece repair and supply house, has just expanded its handpiece subscription solution: now also covering the cutting edge (in the sense of the word) 1:5 speed increasing handpiece BA200LTS and the BA DAC (handpiece cleaning, lubrication and autoclaving machine).

This means that all practices wanting total handpiece and handpiece autoclave cost transparency can have this through the low all-inclusive price with no hassle along the way.

One simple fixed monthly payment from as little as $£ 51.10$ + VAT provides any practice with three fibre optic turbines, LED coupling and ongoing maintenance oil.

Individualised laser marking (also included in the price) allows every busy practice to track the whereabouts of all handpieces at any time, making the Total
Care Solution extremely user friendly in the day to day life of the practice.

All servicing and breakdowns are covered as well as the option of trading the handpieces in or purchasing them outright for a nominal fee at the end of the 36 month subscription period.

As B.A. International is certified to EN ISO 13485:2012 (the quality management system for medical devices), practitioners know that their handpieces are taken care of in a manner worthy of medical devices.

Want to know more? Contact B.A. International on 01604777700 and their friendly staff will be able to advise you.

\section{Upholstery that stays looking good}

A treatment centre is likely to be what patients first notice when they enter your surgery, so whilst functionality may be paramount in your mind, it's also got to look good. Belmont chairs do both. Moreover, the newly launched Ultrasoft Pro upholstery ensures your treatment centre stays looking as good as it did the day it was installed.

The Ultrasoft Pro upholstery is both ink and stain resistant, particularly important with the growing trend for lighter hues. It also offers greater microbial protection and is much more environmentally friendly as the material does not emit any toxic byproducts as $99 \%$ of solvents are recaptured and recycled. The upholstery is available in a diverse colour range to ensure you get just the right shade to complement your practice's decor. In total, there are 33 shades from which you can choose.

Comfort is obviously just as important. Good looks can sometimes belie the comfort of a dental chair, which is why Belmont's upholstery exudes luxury and comfort. Arguably, a comfortable chair is a prerequisite for a relaxed working environment, especially when patients are undergoing lengthy treatments.

Why not pop along to Belmont's Showroom to explore the functionality as well as the comfort of the different models available? For more information visit belmontdental.co.uk.

\title{
Healthy, fresh and odour-free mouths
}

Show your support for National Smile Month and improve the oral health of your patients with CB12 White.

You can help patients to keep their mouth healthy, bright, fresh and odour-free with CB12 White. This innovative mouthwash has been developed by dentists and has a patented formula that enhances oral hygiene levels and has whitening effects too.

Unlike some mouthwashes that merely mask unpleasant smells, CB12 White actually targets and neutralises odorous breath gases with long lasting effects. It also contains anti-plaque agents and fluoride to help strengthen the teeth and prevent decay.

The magic of CB12 White is that when it is used twice a day for two weeks, your patients will see a natural whitening effect that is sure to keep them motivated. It is non-abrasive and non-alcoholic but it has the technology to lift tooth stains and prevent new stains from developing, even in hard to reach areas.

To keep your patients smiling brightly during National Smile Month and beyond, contact CB12 today. Visit www.cb12.com.

\section{Open evenings for postgraduate implantology course}

The ICE Postgraduate Dental Institute \& Hospital will be hosting two Open Evenings for dentists on 2 May and 27 June. These free events are aimed at dentists who want to progress their career in implants and are interested in applying to the MSc/PGDip in Dental Implantology course at ICE.

This is a great opportunity to find out more about how ICE supports students by providing all patients, using a unique mentoring approach and applying evidence-based teaching. Current students and implant experts will also be attending the event and will be able to answer any questions you may have about the course.

The Open Evenings will include a taster lecture on Medico-legal Case studies by Dr Simon Wright followed by a Q\&A.

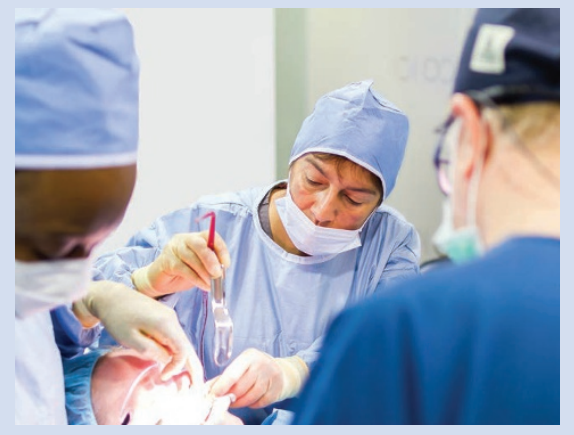

Attendees will also have the chance to see the ICE purpose-built facilities in the form of a guided tour.

To reserve a place and find out more about the course visit: http://icedentalimplants.co.uk/msc-implantology/ or contact Pos, Marketing Executive, on 01614138336 or poseidonia.brazier@ icedental.institute. 